This item was submitted to Loughborough's Research Repository by the author.

Items in Figshare are protected by copyright, with all rights reserved, unless otherwise indicated.

\title{
Direct FTIR assay of streptomycin in agar
}

PLEASE CITE THE PUBLISHED VERSION

PUBLISHER

(C) Springer

LICENCE

CC BY-NC-ND 4.0

REPOSITORY RECORD

Meanwell, Richard J.L., and Gilbert Shama. 2008. "Direct FTIR Assay of Streptomycin in Agar". figshare. https://hdl.handle.net/2134/3483. 
This item was submitted to Loughborough's Institutional Repository by the author and is made available under the following Creative Commons Licence conditions.

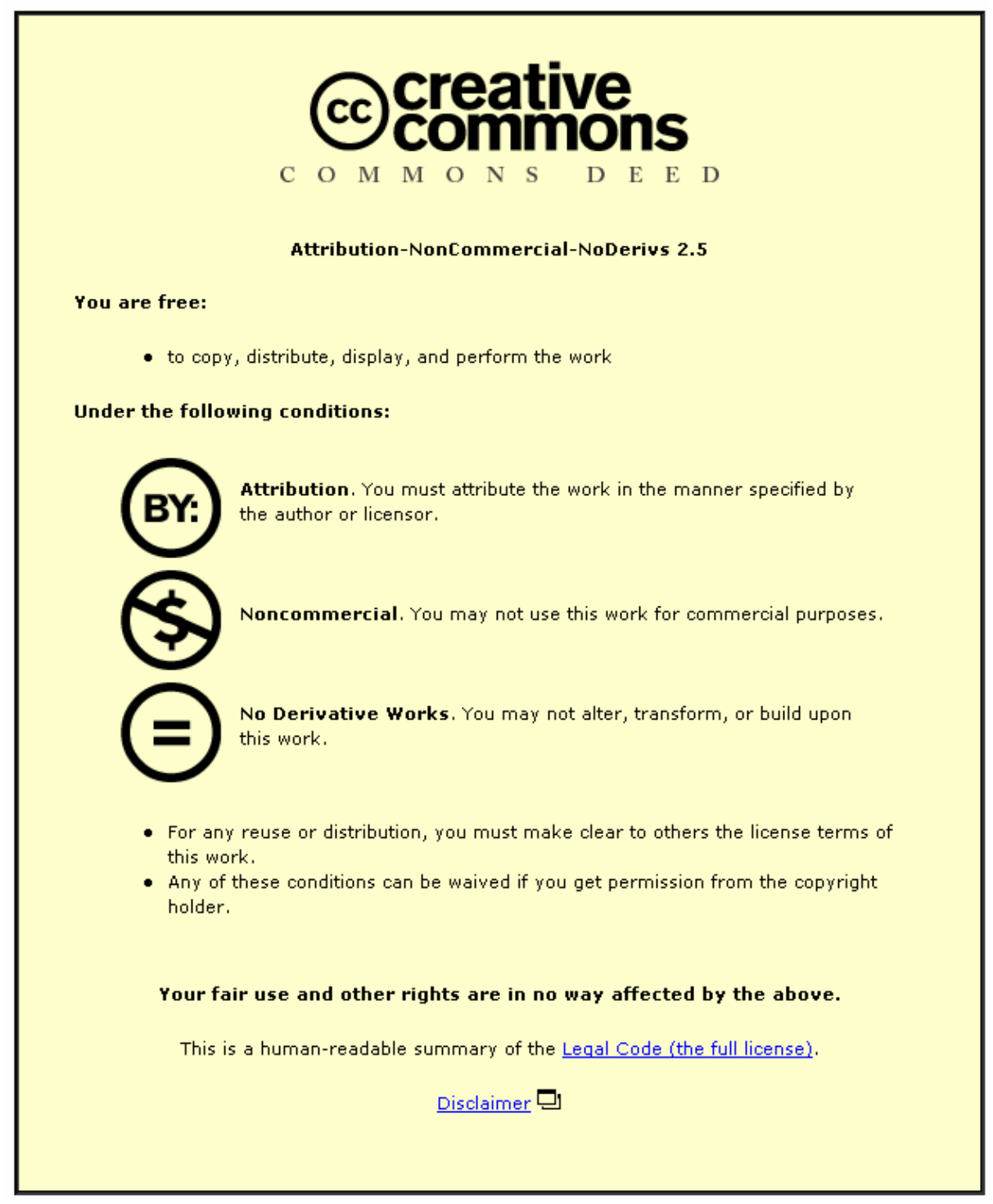

For the full text of this licence, please go to: http://creativecommons.org/licenses/by-nc-nd/2.5/ 


\title{
Direct FTIR assay of streptomycin in agar
}

\author{
Richard J.L. Meanwell and Gilbert Shama* \\ Department of Chemical Engineering, \\ Loughborough University, Loughborough, Leics., LE11 3TU. \\ *Author for correspondence. FAX: +44 (0)1509 223923. email: \\ G.Shama@Lboro.ac.uk
}

Key words: bioassay, FTIR, streptomycin assay, Streptomyces griseus.

\begin{abstract}
Streptomycin titres in samples of agar media on which various species of streptomycetes were cultured were obtained by Fourier Transform Infra Red (FTIR) spectroscopy. Titres were directly comparable to those obtained by bioassay based on Bacillus subtilis inhibition. Analysis by this method could be used to facilitate the isolation of high level antibiotic-producing mutants.
\end{abstract}

\section{Introduction}

The isolation of high level antibiotic producing strains of micro-organisms has traditionally been performed by first plating out a mutagenised population of cells onto agar and allowing colonies to form so that they can be picked off individually. Following this, colonies are typically cultivated in liquid media, normally in 
Erlenmeyer flasks, for assay (Hunter, 1999). Antibiotic production is conventionally established by bioassay or, more commonly now, using increasingly sophisticated analytical techniques (Horie et al. 2001). In the pharmaceutical industry these procedures have largely been robotised and are referred to as "high throughput screening" (Beggs et al. 1999).

We sought to decrease the number of stages required for the isolation of mutants by directly assaying the agar onto which mutants are initially plated using FTIR. The principles involved are illustrated here with reference to the aminoglycoside antibiotic streptomycin using both a culture collection strain of Streptomyces griseus and our own isolates.

\section{Materials and Methods}

Micro-organisms \& cultivation

Streptomyces griseus NCIMB 8136 was purchased in lyophilised form (NCIMB, Aberdeen, UK). Putative Streptomyces species were isolated from a compost heap using chitin agar by the methods described by Hsu \& Lockwood (1975). Spores of all these organisms were maintained on sterile soil. For bioassay, cultivation took place in a yeast - malt extract liquid medium (NCIMB Medium No. 29) in Erlenmeyer flasks for $96 \mathrm{~h}$ at $100 \mathrm{rpm}$ and $28^{\circ} \mathrm{C}$. In order to conduct FTIR analyses on agar, streptomycetes were cultivated on yeast-malt extract agar for $96 \mathrm{~h}$ at $28^{\circ} \mathrm{C}$. 


\section{Bioassay}

The procedure used here was based on the inhibition of the growth of Bacillus subtilis, NCIMB 8054 (Cunniff, 1998). The only variation introduced was that the spores of $B$. subtilis used for seeding the agar were produced by the method of Harnulv and Snygg (1972). Aliquots of filtered culture broths (150 $\mu 1)$ were added to wells cut into agar plates which were subsequently incubated for $48 \mathrm{~h}$ at $30^{\circ} \mathrm{C}$. Zones of inhibition were measured using Vernier callipers. All determinations were performed at least in duplicate. A standard calibration curve was obtained using aqueous solutions of streptomycin (Sigma Aldrich).

Fourier Transform Infra Red Analysis

Assays were conducted on agar samples on which streptomycetes had been cultured or on agar that had been spiked with streptomycin. In the former case, surface mycelium was first scraped off using a scalpel. Samples of agar (c. $0.5 \mathrm{~g})$ were vacuum freeze dried overnight. The resulting solids were then ground and passed through a $56 \mu \mathrm{m}$ sieve. The ground material was mixed with $20 \mu \mathrm{m} \mathrm{KBr}$ to give a final concentration of $0.5 \%(\mathrm{w} / \mathrm{w})$ and pressed into discs. DRIFT analyses were performed, at least in duplicate, using a Fourier Transform Infra Red spectrometer (Model 20DXC, Nicolet Instrument Corp., Madison, WI. USA) equipped with a diffuse reflectance fitting. Analyses of the spectra produced were carried out using Omnic Software. 


\section{Results and Discussion}

Figure 1 shows the FTIR spectrum obtained for agar with streptomycin with the peak at a wavenumber in the vicinity of $1650 \mathrm{~cm}^{-1}$ that was used for assaying the antibiotic highlighted. The spectrometer response (as a function of streptomycin concentration) is illustrated in Figure 2 and clearly shows a strong linear function. Antibiotic titres in agar using FTIR were obtained for S. griseus and two putative streptomycetes isolates (Figure 3). S. griseus 8136 clearly produced the highest antibiotic titre whilst the two compost heap isolates produced only relatively small amounts. Also shown in Figure 3, are antibiotic titres obtained using the $B$. subtilis bioassay. A remarkably similar pattern emerges, particularly as the bioassays were conducted on samples taken from liquid cultures.

Analysis of the IR spectra produced using correlation charts revealed that the peak identified in Figure 1 corresponds to deformation vibration or 'bending' of $-\mathrm{NH}$ groups of streptomycin (Williams \& Fleming, 1989). In a short communication, Strauss (1974) first proposed the use of IR spectra for screening of new antibiotics by comparing selected regions of FTIR spectra. However, no experimental details were provided and it is not clear exactly how the IR spectra were obtained. In contrast, this work provides a quantitative method for assaying antibiotics at an early stage of programmes for selecting high-yielding mutants. Unfortunately, we did not have access to industrial strains of $S$. griseus with which to conduct our assay as such strains produce very much higher streptomycin titres than the type strain (Butler, 1996). However, Figure 2 shows that a linear spectrometer response was obtained for 
higher streptomycin titres than exhibited by the strains used here and the method should therefore be applicable for mutant selection in industry.

In addition to its potential as an assay, the procedure developed here could be adapted for searching for novel antibiotics along the lines suggested by Strauss (1974).

Moreover, with the current trend for robotising assays, this procedure could readily be modified for high throughput screening.

\section{Acknowledgements}

The authors wish to thank Dr. Ian Sutherland of the Department of Chemistry, Loughborough University for providing access to an IR spectrometer and for useful discussion on method development.

\section{References}

Beggs M, Blok M, Diels A (1999) The high throughput screening infrastructure: The right tools for the task. J. Biomol. Screen. 4: 143-149.

Butler PR, Brown M, Oliver SG (1996) Improvement of antibiotic titres from Streptomyces bacteria by interactive continuous selection. Biotech. Bioeng. 49: $185-$ 196. 
Cunniff P (1998) Official Method 962.14, Chapter 33, pp 41-3, Association of Official Analytical Chemists (AOAC) Official Methods of Analysis, $16^{\text {th }}$ Edition. Volume 2, AOAC International, Gaithersburg, MD., USA.

Harnulv BG, Snygg BG (1972) Heat-resistance of Bacillus subtilis spores at various water activities. J. Appl. Bact. 35: 615 - 624 .

Horie M, Yoshida T, Kikuchi Y, Nakazawa H (2001) Determination of streptomycin and dihydrostreptomycin in meat by liquid chromatography/mass spectrometry. J. Food Hyg. Soc. Japan. 42: 374-378.

Hsu SC, Lockwood JL (1975) Powdered chitin agar as a selective medium for enumeration of Actinomycetes in water and soil. Appl. Microbiol. 29: 422-426.

Hunter IS (1999) Microbial synthesis of commercial products and strain improvement. In El-Mansi EMT, Bryce CFA, eds. Fermentation Microbiology and Biotechnology, London: Taylor and Francis Ltd., pp 121-145.

Strauss DG (1974) A fast comparison of IR-spectra for screening new antibiotics J. Antibiot. 27: 805-808.

Williams, DH and Fleming, I (1989) Spectroscopic Methods in Organic Chemistry ( $4^{\text {th }}$ Ed.), London: McGraw-Hill. 
Figure 1. FTIR Spectrum of Streptomycin. The spectrum was obtained by subtracting that for agar from that with agar to which had been added streptomycin.

Figure 2. Calibration of Spectrometer Response

Figure 3. Comparison of Streptomycin Titres obtained by FTIR and Bioassay for different Streptomyces species.

$\square$ FTIR $\square$ Bioassay 


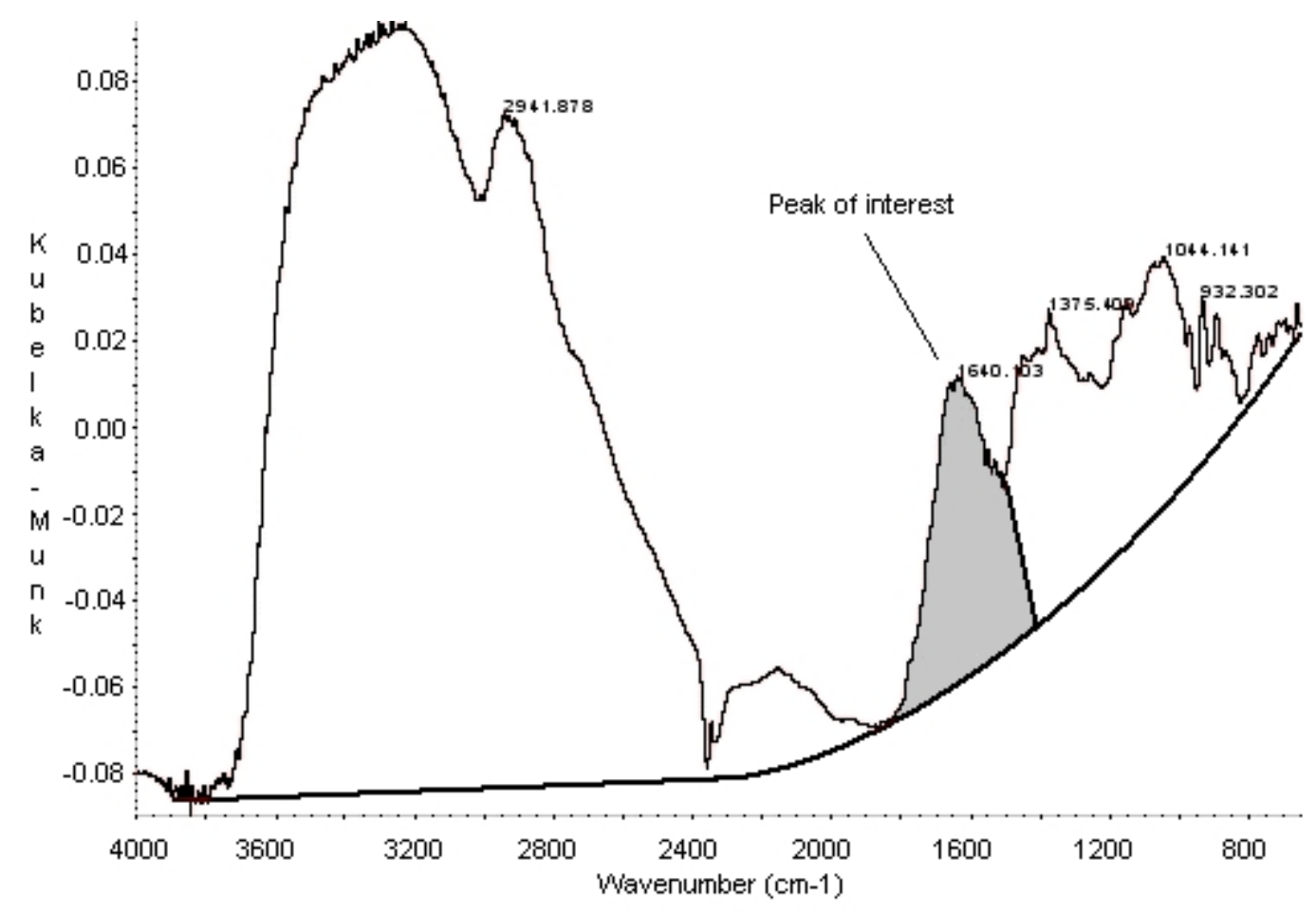




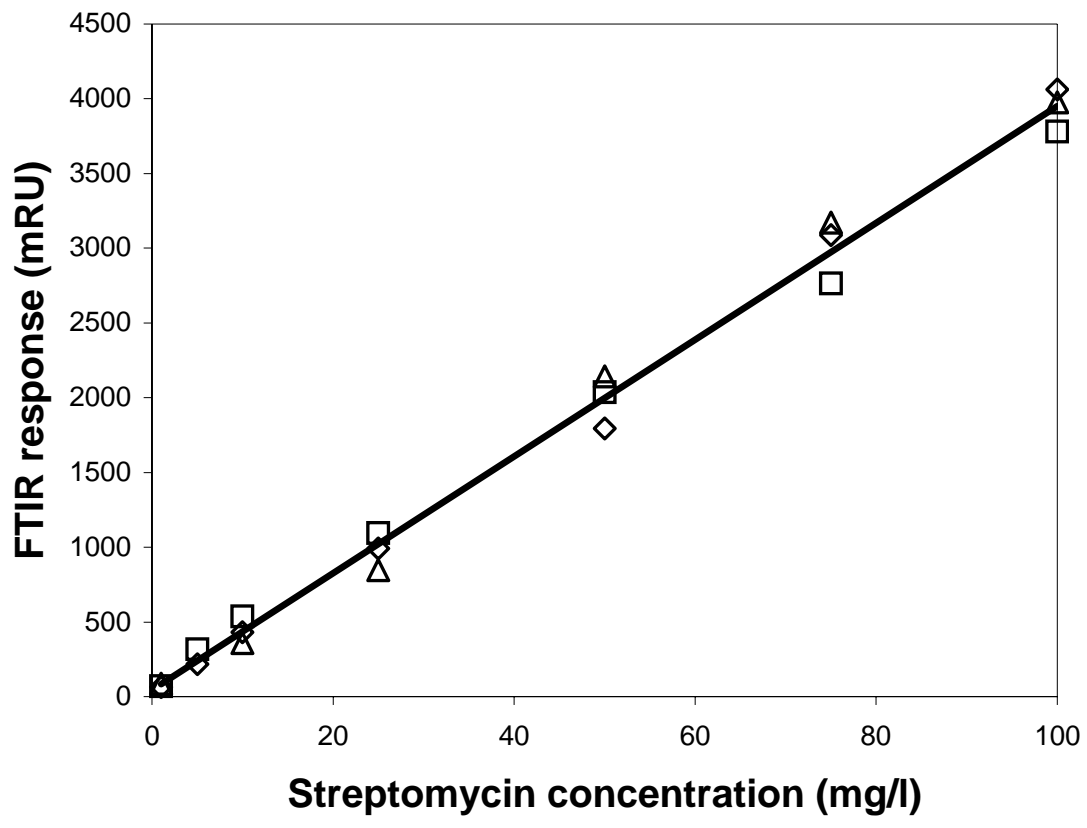




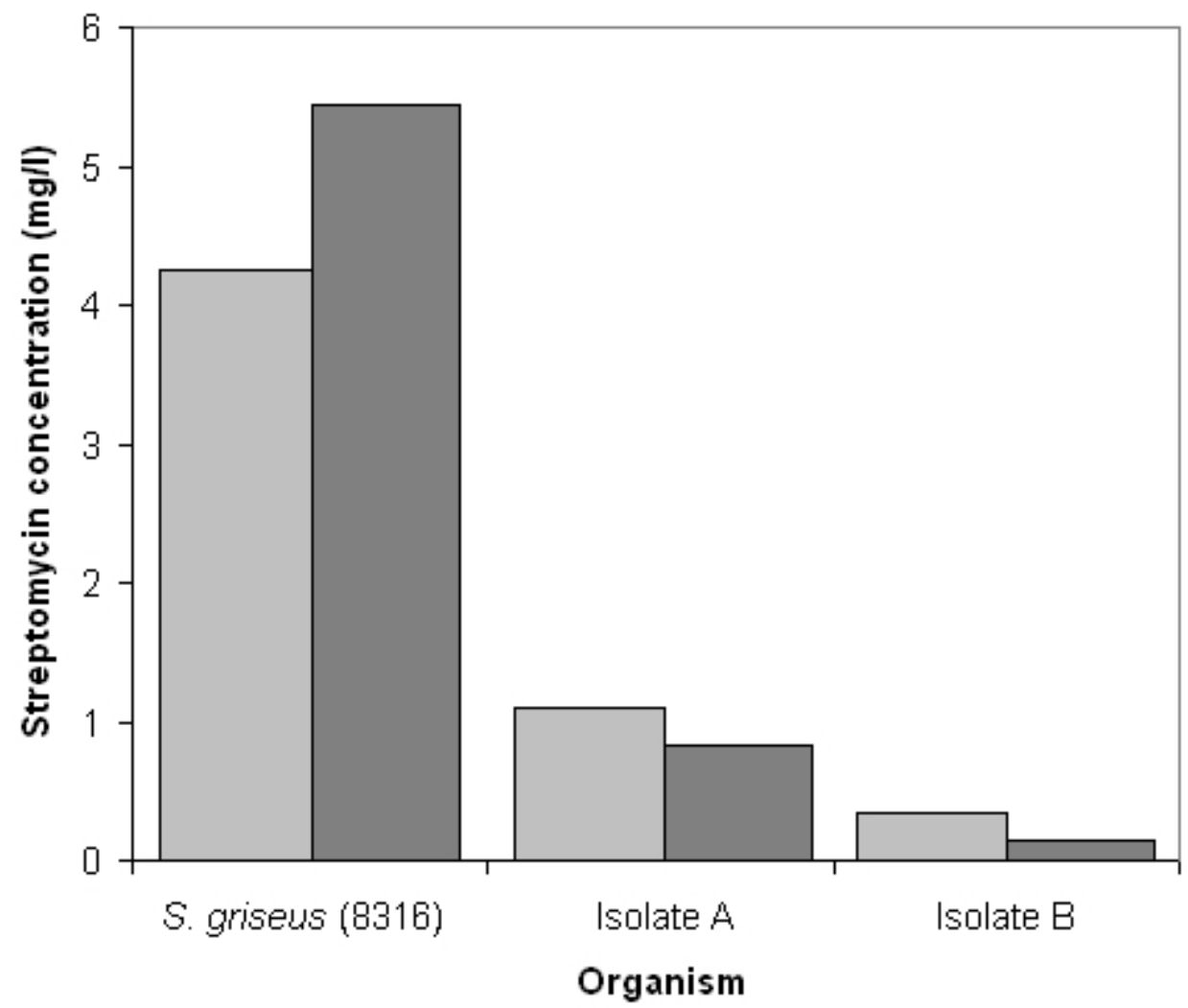

